\title{
Factors associated with genital human papillomavirus infection among adult females in the United States, NHANES 2007-2010
}

\author{
Runhua Shi*, Srinivas Devarakonda, Lihong Liu, Hannah Taylor and Glenn Mills
}

\begin{abstract}
Background: Patients with human papillomavirus (HPV) infection are at risk of developing cancer later in their life. Current research estimates the prevalence of genital HPV infection and explores the factors that are associated with the infection.

Findings: The National Health and Nutrition Examination Survey 2007-2010 was used in this research study. The study population included females in the United States aged 18-59 years. The weighted prevalence of HPV infection was $41.9 \%$. An estimated $59.4 \%$ of non-Hispanic black females had HPV infection. In a multivariate analysis, number of sexual partners, race, age, education level, marital status, income, smoking, and insurance status were associated with HPV infection. HPV infection was 5.77 times more likely for women with $>11$ sexual partners compared to women with 0-1 partners. Non-Hispanic black females were 1.87 times more likely to have HPV infection compared to non-Hispanic white females. Participants with only a high school degree had a 58\% increased prevalence compared to college-educated women. Uninsured women had a 39\% increased prevalence compared to those with insurance.
\end{abstract}

Conclusion: This study found that $41.9 \%$ of U.S. females aged 18-59 years tested positive for genital HPV infection. We determined that individuals with more sexual partners, with a lower education level, with non-Hispanic black race, and with no insurance were the populations at greatest risk. It is necessary to continue monitoring the prevalence of this infection in the general population to provide a basis for effective treatment and prevention in the target populations.

Keywords: Human Papillomavirus, Sexual behaviors, Prevalence Ratio, Survey

\section{Findings}

Genital human papillomavirus (HPV) is the most common sexually transmitted infection in the United States. HPV includes a group of more than 150 related viruses. Many of these viruses can be easily spread through direct skin contact during sexual intercourse [1]. More than $50 \%$ of individuals engaging in sexual activities are infected with at least one type of HPV in their lifetime. An estimated $42.5 \%$ of U.S. females aged $14-59$ years had a genital HPV infection in 2003-2006 [2]. Some patients with HPV infection can be restored back to health, while infection progresses to cancer in others [3].

\footnotetext{
* Correspondence: rshi@lsuhsc.edu

Department of Medicine, Feist-Weiller Cancer Center, LSU Health Shreveport, Shreveport, LA, USA
}

\section{() Biomed Central

More than $40 \mathrm{HPV}$ types can infect the genital areas of men and women [4]. These types can be classified as high-risk, probable high-risk, low-risk, and undetermined risk for the development of cervical cancer. Low-risk types (HPV 6, 11) are mostly associated with genital warts. High-risk types (HPV 16, 18) can contribute to precancerous lesions, low-grade cervical intraepithelial lesions and high-grade cervical intraepithelial lesions, as well as anogenital cancers [5]. HPV infection is a major cause of cervical cancer [6], and 11,818 women in the U.S. were diagnosed with cervical cancer in 2010 [7].

The primary goals of our current research are to identify the potential factors associated with HPV infection and to estimate the prevalence of infection for U.S. females from 2007 to 2010. Eventually, we aim to help create programs targeting high-prevalence populations to 
prevent HPV infection and lower their risk of getting cervical cancer.

\section{Methods and materials}

Data was obtained from the National Health and Nutrition Examination Survey (NHANES) 2007-2010 [8]. The survey data includes information about demographic and socioeconomic status, mental health, and dental health, as well as physiological and laboratory measurements. The survey interviews about 12,000 people biannually.

\section{Survey design and population}

The NHANES used a multistage probability sample design to select the participants. Consenting participants completed a household interview followed by a physical examination and interviews at a Mobile Examination Center (MEC). Non-Hispanic (NH) black and low income groups were oversampled in the NHANES to allow for an accurate statistical estimation in these population groups [9]. The protocol was approved by the National Center for Health Statistics (NCHS) institutional review board. Further information regarding study design and methods for oversampling is available on the NHANES website [8].

From 2007 to 2010, 10,010 females of all ages were interviewed. The combined unweighted household interview response rate for that period was $78.9 \%$; the examination response rate was 76.3\%. All females aged 18-59 years $(n=4242)$ who visited the MEC were asked to selfcollect a cervicovaginal swab sample. Out of all samples collected, 3738 (88.1\%) were reported as positive or negative and were used in the final analysis. Combining the data for years 2007 through 2010 was justified. There was no significant difference in HPV prevalence between 2007-2008 and 2009-2010 for all but 5 of 37 HPV types, as detected by the Linear Array assay (data not shown).

\section{Demographic and behavioral data}

Demographic information, including gender, age, race, education, marital status, and country of birth, was obtained from all participants during the household interviews. The poverty index was calculated according to the U.S. Census definition. This method divides total family income by the poverty threshold after adjusting for family size at the time of the interview.

Sexual history information, including if the participant had ever had sex and the age of first sexual experience, was self-reported by participants using an audio computer-assisted self-interview. Respondents who reported having sex (described as vaginal, oral, or anal) were asked additional questions about their lifetime sexual history and about any sexual encounters in the prior 12 months. These additional questions addressed number of sexual partners, sexual orientation, and condom usage.
Specimen collection and processing, laboratory methods As described by Dunne et al. [10], self-collected cervicovaginal swab samples were obtained from female participants aged 18-59 who had an examination in the MEC. Swabs were given to the NHANES personnel, stored at room temperature, and mailed within 1 week to the Centers for Disease Control and Prevention (CDC) laboratory. There, they were kept at $4^{\circ} \mathrm{C}$ and extracted within 1 month of collection.

Multiplex polymerase chain reaction (PCR) was used for detection of $37 \mathrm{HPV}$ types within the Alphapapillomavirus genera. Samples were reported as HPV positive if any of the $37 \mathrm{HPV}$ deoxyribonucleic acid (DNA) types were detected, including high-risk $(16,18,26,31,33,35$, $39,45,51,52,53,56,58,59,66,68,73,82)$ and low-risk $(6,11,40,42,54,55,61,62,64,67,69,70,71,72,81,82$ subtype IS39, 83, 84, 89) types. If the strips were positive for any of the types, the sample was coded as positive. If the strips were negative for all of the types and betaglobin was detected, the sample was coded as negative. If there was no beta-globin present in the sample and no HPV type was detected, the sample was coded as inadequate $[8,11-14]$.

\section{Statistical analysis}

We estimated the overall prevalence of infection for any HPV type with respect to sociodemographic and sexual behavioral characteristics. Due to the complexity of the design, all estimates were measured using 4-year MEC sample weights provided by NCHS to account for the unequal probabilities of selection and adjustment for nonresponse. The weighting methodology has been described previously [10]. Taylor series linearization was used to estimate variance in a complex cluster survey design [15]. Confidence intervals (CIs) were calculated using a logit transformation with the standard error of the logit prevalence based on the delta method and applying SUDAAN estimated standard errors [16].

The Wald $\chi^{2}$ statistic was used to assess bivariate association between HPV and sociodemographic or behavioral characteristics. No adjustments were made to the p-values for multiple comparisons. An unconditional logistic regression model was used to determine associations between genital HPV infection and these factors. Variables for adjustment in multivariate logistic regression models were selected based on bivariate associations with $\mathrm{p}$-values $<0.2$. Goodness of fit for the final step of the model was assessed using the Hosmer-Lemeshow Satterthwaite adjusted $F$ test.

SAS software version 9.4 for Windows (SAS Institute Inc. Gary, North Carolina) and SAS callable SUDAAN 11.0.1 [17] were used for the statistical analyses. Twosided p-values less than 0.05 were considered statistically significant. 


\section{Results}

HPV types and species by oncogenic risk category are presented in Figure 1. In the NHANES 2007-2010, there were 3738 females aged 18 to 59 years with an HPV evaluation result in the final analysis. The $37 \mathrm{HPV}$ types were grouped as high-risk (Figure 1 Left Panel) or low-risk (Figure 1 Right Panel). The prevalence of high-risk HPV types 33 and 58 was less than 2\%; HPV strains 16 and 18 had a prevalence of $4.92 \%$ and $1.77 \%$, respectively. HPV strain 53 had the highest prevalence of $6.26 \%$ in the highrisk HPV category, and HPV strain 62 had the highest prevalence of $5.93 \%$ in the low-risk category.

In a univariate analysis (Table 1), the overall weighted prevalence of HPV infection was $41.9 \%$. An estimated $59.4 \% \mathrm{NH}$ black females and $38.7 \%$ of $\mathrm{NH}$ white females, the lowest prevalence, were positive for HPV. There was a statistically significant difference between subjects of different races. The Prevalence Ratio for NH black females was 2.3 times that of $\mathrm{NH}$ white females.

There was a lower trend of HPV infection with increased age, higher education level, and decreased family poverty level. There was a bimodal pattern in the prevalence of
HPV for age, with a high HPV prevalence of $56.1 \%$ in the 18-24 age group and with a second peak in the 40-44 age group. HPV prevalence was $48 \%$ for women with less than a high school education, whereas it was $31.4 \%$ for those with a college education. Participants living in a family with an income-to-poverty ratio (PIR) of $<130 \%$ showed a $55.3 \%$ prevalence of HPV infection. In terms of marital status, prevalence was lowest (29.4\%) for married women and highest $(>47 \%)$ for women classified as single, divorced, or never married.

The association of HPV infection with behavioral factors is presented in Table 2. Females who smoked $<100$ cigarettes in their lifetime (Prevalence Ratio $[\mathrm{PR}]=0.52$ ) were less likely to have HPV infection. Females who did not have health insurance $(\mathrm{PR}=1.9)$ or a routine place to receive health care $(\mathrm{PR}=1.39)$ were more likely to have HPV infection.

Females who reported never having sex were $71 \%$ less likely to have HPV infection compared to females who reported having sex. The prevalence of HPV infection increased $89 \%$ for females having sex before 16 years of age compared to after 16 . There was a trend of increasing

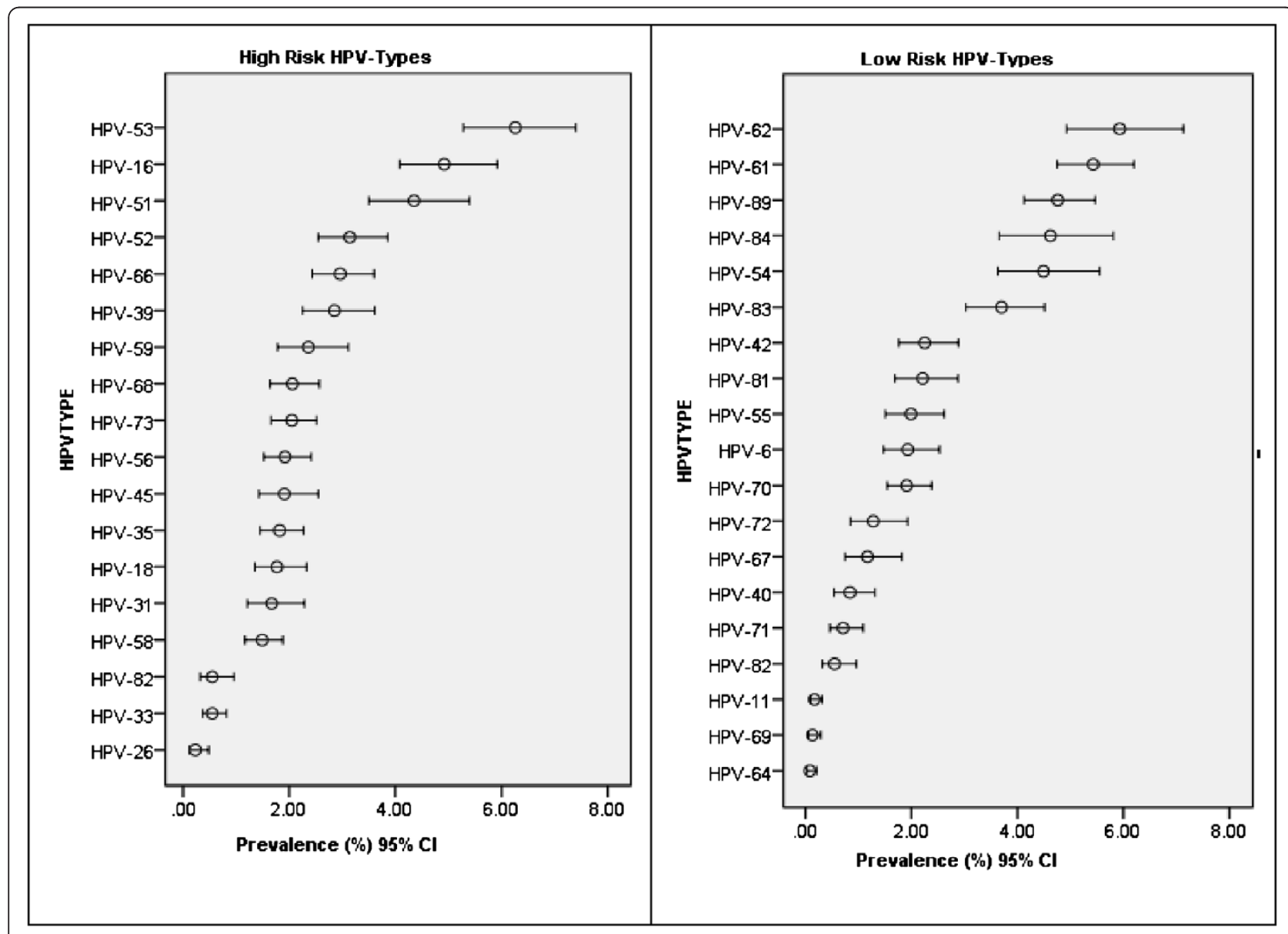

Figure 1 HPV types and species by oncogenic risk category. Left panel, High-Risk HPV Types. Right panel, Low-Risk HPV Types. 
Table 1 Weighted prevalence of HPV infection among female participants ages 18-59 by sociodemographic characteristics NHANES 2007-2010

\begin{tabular}{|c|c|c|c|c|c|c|c|c|c|c|}
\hline & & Sampl & size & & $95 \% \mathrm{Cl}$ & $\% \mathrm{HPV}+$ & & & $95 \% \mathrm{C}$ & of $P R$ \\
\hline & & $\mathrm{HPV}+$ & HPV- & $\mathrm{HPV}+$ & Lower & Upper & $p$-value\# & PR & Lower & Upper \\
\hline & All & 1716 & 2022 & 41.9 & 39.6 & 44.2 & & & & \\
\hline & NH White & 676 & 916 & 38.7 & 36.0 & 41.5 & & 1.00 & & \\
\hline Race & NH Black & 436 & 299 & 59.4 & 54.4 & 64.2 & $<00001$ & 2.32 & 1.90 & 2.83 \\
\hline Hace & Mex. Amer. & 321 & 457 & 41.9 & 38.1 & 45.7 & 0. & 1.14 & 0.97 & 1.34 \\
\hline & Other & 283 & 350 & 40.7 & 35.3 & 46.4 & & 1.09 & 0.85 & 1.38 \\
\hline & $18-24$ & 383 & 287 & 56.1 & 51.4 & 60.7 & $<00001$ & 1.00 & & \\
\hline & $25-29$ & 222 & 192 & 50.8 & 45.9 & 55.6 & - 0.0001 & 0.81 & 0.64 & 1.01 \\
\hline & $30-34$ & 189 & 244 & 40.1 & 33.8 & 46.7 & & 0.52 & 0.39 & 0.70 \\
\hline$\Delta \rho \rho^{\prime}$ & $35-39$ & 203 & 267 & 38.3 & 33.6 & 43.2 & - & 0.49 & 0.36 & 0.65 \\
\hline ye & $40-44$ & 182 & 295 & 34.5 & 30.4 & 38.9 & & 0.41 & 0.33 & 0.53 \\
\hline & $45-49$ & 227 & 256 & 44.4 & 39.2 & 49.8 & & 0.63 & 0.48 & 0.81 \\
\hline & $50-54$ & 172 & 266 & 33.4 & 27.1 & 40.4 & & 0.39 & 0.29 & 0.53 \\
\hline & $55-59$ & 138 & 215 & 34.0 & 27.3 & 41.4 & & 0.40 & 0.29 & 0.56 \\
\hline & $>=$ College & 243 & 480 & 31.4 & 27.4 & 35.6 & (2) & 1.00 & & \\
\hline & $<$ High School & 486 & 484 & 48.0 & 43.6 & 52.3 & -0.0001 & 2.02 & 1.54 & 2.63 \\
\hline Luticativit & High School & 430 & 418 & 47.5 & 42.2 & 52.8 & & 1.98 & 1.54 & 2.54 \\
\hline & Some College & 554 & 637 & 43.5 & 39.3 & 47.9 & 0.001 & 1.69 & 1.34 & 2.13 \\
\hline & Married & 562 & 1154 & 29.4 & 26.8 & 32.2 & & 1.00 & & \\
\hline & Wid/Div/Sep & 393 & 278 & 58.3 & 53.4 & 63.0 & & 2.96 & 2.08 & 4.20 \\
\hline Marital Status & Never married & 457 & 322 & 55.6 & 50.0 & 61.0 & $<0.0001$ & 2.10 & 1.50 & 2.94 \\
\hline & Living W Partner & 188 & 157 & 55.2 & 47.1 & 63.1 & & 3.00 & 2.46 & 3.66 \\
\hline & Missing & 116 & 111 & 46.7 & 39.3 & 54.3 & & 3.35 & 2.68 & 4.19 \\
\hline & $P I R:>=350 \%$ & 343 & 620 & 33.3 & 29.4 & 37.4 & $<0.0001$ & 1.00 & & \\
\hline Ratio of family income to poverty & PIR:130-349\% & 541 & 655 & 43.0 & 39.2 & 47.0 & $<0001 *$ & 1.42 & 1.19 & 1.71 \\
\hline & $\mathrm{PIR}<130 \%$ & 691 & 581 & 55.3 & 51.9 & 58.6 & & 2.33 & 1.90 & 2.84 \\
\hline & US & 1338 & 1437 & 42.7 & 40.0 & 45.4 & & 1.00 & & \\
\hline Country of Birth & Mexico & 161 & 281 & 35.6 & 30.7 & 40.8 & 0.1095 & 0.743 & 0.598 & 0.923 \\
\hline & Other & 217 & 304 & 39.1 & 33.0 & 45.6 & & 0.863 & 0.651 & 1.142 \\
\hline
\end{tabular}

\#P-value: Chi-Square Test; *P-value ( $\mathrm{p}$-values for $\mathrm{CMH}$ trend analysis, without missing categories), PR: Prevalence Ratio.

HPV infection in women with a higher number of sexual partners in their lifetime (or yearly). The prevalence of infection was 8.9 times higher for women with $>11$ sexual partners in their lifetime compared to women with 0-1 partners. This trend was noticed among all races. Overall, $\mathrm{NH}$ black females showed the highest prevalence of HPV infection regardless of their number of partners (Figure 2). Compared to women who used a condom during sex, those who did not use a condom had twice the prevalence of HPV infection. Lastly, women who identified themselves as being 'lesbian' or 'bisexual' had a $72 \%$ increased prevalence of HPV infection compared to those who identified as 'straight.'

In a multivariate logistic regression analysis, adjusting for other factors, the number of lifetime sexual partners had a significant association with HPV infection. HPV infection was 5.77 times more likely for women with > 11 partners compared to women with 0-1 partners. $\mathrm{NH}$ black females were 1.87 times more likely to have an HPV infection compared to $\mathrm{NH}$ white females. Age was negatively associated with the prevalence of HPV, except for an increased peak in the 44-49 age group. Having a college degree and being married were also associated with lower HPV prevalence. Family income-topoverty ratio, a habit of smoking cigarettes, and insurance status remained significant factors associated with HPV infection.

When the results were adjusted for other factors, country of birth, recreational drug usage, ever having sex, age at first sexual encounter, condom usage during sex, and 
Table 2 Weighted prevalence of HPV among female participants ages 18-59 by behavioral factors

\begin{tabular}{|c|c|c|c|c|c|c|c|c|c|c|}
\hline & & \multicolumn{2}{|c|}{ Sample size } & \multirow{2}{*}{$\begin{array}{l}\% \\
\text { HPV+ }\end{array}$} & \multicolumn{2}{|c|}{$95 \% \mathrm{Cl}$ of $\% \mathrm{HPV}+$} & \multirow[t]{2}{*}{$p$-value\# } & \multirow[b]{2}{*}{ PR } & \multicolumn{2}{|l|}{$95 \% \mathrm{Cl}$} \\
\hline & & $\mathrm{HPV}+$ & HPV- & & Lower & Upper & & & Lower & Upper \\
\hline \multirow{3}{*}{ Smoked $\geq 100$ cigarettes in life } & Yes & 763 & 608 & 51.2 & 47.3 & 55.1 & \multirow{3}{*}{$<.0001$} & 1.00 & & \\
\hline & No & 838 & 1304 & 35.3 & 32.5 & 38.3 & & 0.52 & 0.44 & 0.62 \\
\hline & Missing & 115 & 110 & 45.7 & 38.3 & 53.3 & & 0.80 & 0.56 & 1.15 \\
\hline \multirow{3}{*}{ Drug Use } & Yes & 857 & 713 & 49.0 & 45.4 & 52.7 & \multirow{3}{*}{$<.0001$} & 1.00 & & \\
\hline & No & 642 & 1066 & 33.2 & 30.0 & 36.4 & & 0.79 & 0.58 & 1.06 \\
\hline & Missing & 217 & 243 & 43.0 & 37.3 & 48.9 & & 0.52 & 0.43 & 0.62 \\
\hline \multirow{2}{*}{ Covered by health insurance } & Yes & 1157 & 1494 & 38.5 & 35.6 & 41.5 & \multirow{2}{*}{$<.0001$} & 1.00 & & \\
\hline & No & 557 & 524 & 54.4 & 51.1 & 57.7 & & 1.90 & 1.58 & 2.29 \\
\hline \multirow{2}{*}{ Routine place for health care } & Yes & 1443 & 1736 & 41.0 & 38.5 & 43.5 & \multirow{2}{*}{0.0057} & 1.00 & & \\
\hline & No & 273 & 285 & 49.0 & 43.6 & 54.5 & & 1.39 & 1.10 & 1.75 \\
\hline \multirow{3}{*}{ Ever had vaginal, anal, or oral sex } & Yes & 1467 & 1659 & 42.6 & 40.2 & 45.1 & \multirow{3}{*}{$<.0001$} & 1.00 & & \\
\hline & No & 33 & 118 & 17.6 & 11.9 & 25.4 & & 0.29 & 0.19 & 0.43 \\
\hline & Missing & 216 & 245 & 43.1 & 37.3 & 49.1 & & 1.02 & 0.78 & 1.33 \\
\hline \multirow{3}{*}{ How old when first had sex } & $>=16$ years & 489 & 357 & 54.5 & 50.0 & 58.8 & \multirow{3}{*}{$<.0001$} & 1.00 & & \\
\hline & $<16$ years & 976 & 1296 & 38.8 & 36.2 & 41.4 & & 1.89 & 1.59 & 2.24 \\
\hline & Missing & 251 & 369 & 37.1 & 32.2 & 42.3 & & 0.93 & 0.74 & 1.18 \\
\hline \multirow{6}{*}{ \#male sex partners lifetime } & $0-1$ & 139 & 514 & 14.8 & 12.0 & 18.1 & \multirow{6}{*}{$\begin{array}{l}<.0001 \\
<.0001^{*}\end{array}$} & 1.00 & & \\
\hline & $2-3$ & 264 & 429 & 31.2 & 27.2 & 35.5 & & 2.61 & 2.05 & 3.32 \\
\hline & $4-5$ & 298 & 289 & 45.8 & 39.6 & 52.1 & & 4.87 & 3.51 & 6.75 \\
\hline & $6-10$ & 422 & 306 & 54.3 & 49.5 & 59.1 & & 6.85 & 5.40 & 8.69 \\
\hline & $11+$ & 334 & 180 & 60.7 & 55.5 & 65.6 & & 8.90 & 6.41 & 12.35 \\
\hline & Missing & 259 & 304 & 42.3 & 37.4 & 47.4 & & 4.23 & 3.08 & 5.81 \\
\hline \multirow{5}{*}{ \#male sex partners yearly } & 0 & 194 & 338 & 33.7 & 28.8 & 38.9 & \multirow{5}{*}{$\begin{array}{l}<.0001 \\
<0.001^{*}\end{array}$} & 1.00 & & \\
\hline & 1 & 929 & 1283 & 37.3 & 34.9 & 39.7 & & 1.09 & 0.93 & 1.27 \\
\hline & 2 & 178 & 57 & 74.8 & 66.8 & 81.5 & & 4.10 & 2.96 & 5.70 \\
\hline & $3+$ & 159 & 32 & 85.2 & 77.0 & 90.9 & & 6.89 & 4.61 & 10.30 \\
\hline & Missing & 256 & 312 & 41.3 & 36.6 & 46.3 & & 1.28 & 1.06 & 1.55 \\
\hline \multirow{6}{*}{ \#times had sex without condom/year } & Never & 288 & 356 & 40.9 & 35.7 & 46.3 & \multirow{6}{*}{$\begin{array}{l}<.0001 \\
<0011^{*}\end{array}$} & 1.00 & & \\
\hline & $<$ half of the time & 185 & 123 & 58.6 & 51.6 & 65.2 & & 1.10 & 0.88 & 1.38 \\
\hline & half of the time & 99 & 57 & 63.5 & 54.6 & 71.5 & & 2.25 & 1.59 & 3.19 \\
\hline & $>$ half of the time & 120 & 83 & 56.3 & 48.8 & 63.5 & & 2.76 & 2.00 & 3.82 \\
\hline & Always & 546 & 716 & 38.6 & 35.3 & 42.0 & & 2.05 & 1.48 & 2.84 \\
\hline & Missing & 478 & 687 & 37.1 & 33.7 & 40.6 & & 0.94 & 0.79 & 1.12 \\
\hline \multirow{3}{*}{ Describe sexual orientation } & Heterosexual or straight & 1355 & 1639 & 40.9 & 38.4 & 43.6 & & 1.00 & & \\
\hline & $\begin{array}{l}\text { Homosexual/lesbian/ } \\
\text { Bisexual/Other }\end{array}$ & 133 & 111 & 54.4 & 46.2 & 62.4 & 0.0034 & 1.72 & 1.26 & 2.36 \\
\hline & missing & 228 & 272 & 42.5 & 37.2 & 47.9 & & 1.07 & 0.83 & 1.37 \\
\hline
\end{tabular}

\#P-value: Chi-Square Test; *P-value ( $\mathrm{p}$-values for $\mathrm{CMH}$ trend analysis, without missing categories), PR: Prevalence Ratio.

sexual orientation were no longer associated with HPV infection.

\section{Discussion and conclusion}

From the NHANES 2007-2010 data set, we found that the overall prevalence of genital HPV infection was
41.9\% (95\% CI: 39.6-44.2\%) in females aged 18-59 in the United States. We compared this result with two previous NHANES analyses observing data for females in the United States. Our estimate was similar to the result of the first study, which found a $42.5 \%$ (95\% CI: 40.3-44.7\%) prevalence for females aged 14-59 in the 


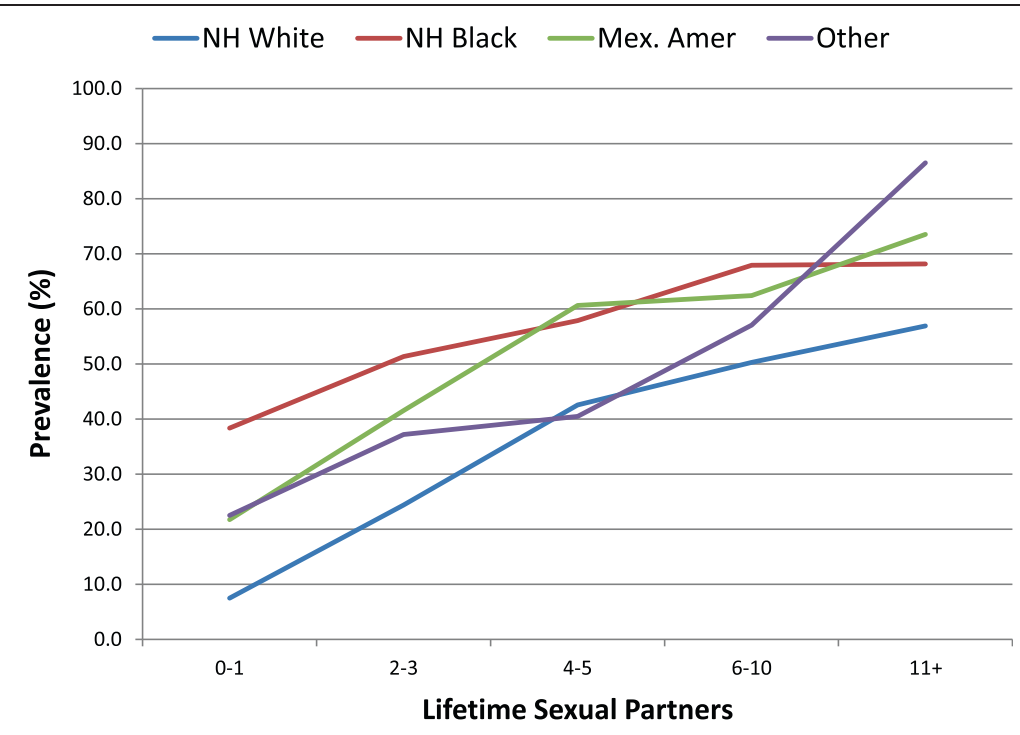

Figure 2 Weighted prevalence of genital HPV among female adult participants aged 18-59 by lifetime sexual partners and race.

2003-2006 data set [2]. The confidence intervals overlapped, indicating no statistical difference between these two estimations. Our estimate was higher than the result of the second study, which found a prevalence of $26.8 \%$ [10] among females, aged 14-59 in the 20032004 data set. This discrepancy could be due to a change in the laboratory methods to detect HPV DNA resulting in increased sensitivity of the test $[2,18,19]$.

In our study, there was a bimodal prevalence of genital HPV for age, consistent with the same two previous NHANES studies $[2,10]$. This may indicate increased sexual activity in the $18-24$ age group $[20,21]$ causing the transmission of HPV by sexual contact. The reason for the increased prevalence in the 45-49 age group is unclear. We speculate that it may be due to an increased incidence [22], a difference in sexual behaviors across birth cohorts [23], or a change in marital status.

HPV infection was associated with certain racial and ethnic groups. NH black females had an increased prevalence even when controlling for factors such as number of sexual partners in their lifetime (Figure 2) or other factors (Table 3). Interestingly, even in the group with $0-1$ sexual partners, $\mathrm{NH}$ black females had twice the prevalence of HPV infection compared to other racial and ethnic groups. This indicates that number of sexual partners is not the only factor that impacts the prevalence of HPV infection.

Some studies have shown an inconsistent association between education level and prevalence [24,25]. However, in others, education level was negatively associated with HPV infection $[2,10]$. In our study, with increased education, the prevalence of HPV infection decreased.
We speculate that this trend could be connected to factors such as increased awareness of HPV or adoption of safe sexual practices. Safe practices might include, but are not limited to, regular usage of condoms and limiting the number of sexual partners. Therefore, health education interventions could be introduced to reduce the HPV prevalence by increasing awareness, encouraging safe sex [26], teaching about the routes of HPV transmission, and promoting the use of the HPV vaccine [27].

The number of sexual partners played a statistically significant role in HPV infection. This finding mirrors those seen in other studies $[2,10]$. We also found an association of health insurance status with HPV infection. A meta-analysis showed that cost of vaccination and lack of insurance coverage are barriers that prevent women from obtaining the vaccine [28]. Individuals with private health insurance are more likely to hear about the HPV vaccine and three times more likely to get the vaccine compared to uninsured patients or those with public insurance plans [29]. In addition, poverty and having smoked $<100$ cigarettes in their lifetime were associated with HPV infection.

In conclusion, $41.9 \%$ of U.S. females aged 18-59 years tested positive for genital HPV infection. This study found that an increased number of sexual partners, a lower level of education, non-Hispanic black race, and a lack of insurance were factors of concern with HPV infection. Continuing to monitor the prevalence of HPV in the general population can establish a basis for possible interventions focusing on at-risk groups. 
Table 3 Multivariate logistic regression analysis of HPV infection with sociodemographic and behavioral factors

\begin{tabular}{|c|c|c|c|c|}
\hline & & & $95 \% \mathrm{Cl}$ & \\
\hline & & $\begin{array}{l}\text { Odds } \\
\text { ratio }\end{array}$ & Lower & Upper \\
\hline & NH White & 1.00 & & \\
\hline Race & Mex. Amer. & 1.50 & 1.16 & 1.95 \\
\hline Hace & NH Black & 1.87 & 1.45 & 2.42 \\
\hline & Other & 1.13 & 0.84 & 1.52 \\
\hline & $18-24$ & 1.00 & & \\
\hline & $25-29$ & 0.81 & 0.57 & 1.15 \\
\hline & $30-34$ & 0.52 & 0.36 & 0.76 \\
\hline Are & $35-39$ & 0.52 & 0.36 & 0.75 \\
\hline Age & $40-44$ & 0.46 & 0.33 & 0.63 \\
\hline & $44-49$ & 0.76 & 0.53 & 1.09 \\
\hline & $50-54$ & 0.48 & 0.34 & 0.68 \\
\hline & $55-59$ & 0.59 & 0.39 & 0.87 \\
\hline & $>=$ College & 1.00 & & \\
\hline Educa & $<$ High School & 1.36 & 0.95 & 1.95 \\
\hline Letreationt & High School & 1.58 & 1.22 & 2.05 \\
\hline & Some College & 1.13 & 0.89 & 1.43 \\
\hline & Married & 1.00 & & \\
\hline & Living W Partner & 1.47 & 1.02 & 2.10 \\
\hline Marital Status & Never Married & 1.74 & 1.34 & 2.25 \\
\hline & Wid/Div/Sep & 2.27 & 1.72 & 3.00 \\
\hline & Missing & 29.66 & 1.93 & 456.93 \\
\hline & $>350 \%$ & 1.00 & & \\
\hline $\begin{array}{l}\text { Ratio of family income } \\
\text { to poverty }\end{array}$ & $<130 \%$ & 1.38 & 1.11 & 1.71 \\
\hline & $130-349 \%$ & 1.06 & 0.87 & 1.29 \\
\hline & US & 1.00 & & \\
\hline Country of Birth & Mexico & 0.81 & 0.57 & 1.15 \\
\hline & Other & 1.35 & 0.94 & 1.94 \\
\hline & $>=100$ Cig/life & 1.00 & & \\
\hline $\begin{array}{l}\text { Smoked at least } 100 \\
\text { cigarettes in life }\end{array}$ & $<100$ Cig/life & 0.78 & 0.62 & 0.99 \\
\hline & Missing & 0.03 & 0.00 & 0.40 \\
\hline & Yes & 1.00 & & \\
\hline Drug Use & No & 1.06 & 0.85 & 1.31 \\
\hline & Missing & 1.15 & 0.36 & 3.73 \\
\hline Covered by health & Yes & 1.00 & & \\
\hline insurance & No & 1.39 & 1.12 & 1.73 \\
\hline Routine place to go & Yes & 1.00 & & \\
\hline & No & 0.95 & 0.72 & 1.26 \\
\hline & Yes & 1.00 & & \\
\hline $\begin{array}{l}\text { Ever had vaginal, anal, } \\
\text { or oral sex }\end{array}$ & No & 0.58 & 0.15 & 2.17 \\
\hline & Missing & 0.96 & 0.18 & 5.17 \\
\hline
\end{tabular}

Table 3 Multivariate logistic regression analysis of HPV infection with sociodemographic and behavioral factors (Continued)

\begin{tabular}{|c|c|c|c|c|}
\hline \multirow{3}{*}{ Age when first had Sex } & $>=16$ years. & 1.00 & & \\
\hline & $<16$ years & 0.94 & 0.79 & 1.12 \\
\hline & Missing & 0.34 & 0.09 & 1.25 \\
\hline \multirow{6}{*}{$\begin{array}{l}\text { \#male sex partners/ } \\
\text { lifetime }\end{array}$} & $0-1$ & 1.00 & & \\
\hline & $2-3$ & 1.99 & 1.46 & 2.72 \\
\hline & $4-5$ & 3.69 & 2.62 & 5.21 \\
\hline & $6-10$ & 4.87 & 3.54 & 6.71 \\
\hline & $11+$ & 5.77 & 3.64 & 9.15 \\
\hline & Missing & 15.21 & 5.12 & 45.18 \\
\hline \multirow{5}{*}{ \#male sex partners/year } & 0 & 1.00 & & \\
\hline & 1 & 0.97 & 0.64 & 1.49 \\
\hline & 2 & 2.17 & 1.10 & 4.28 \\
\hline & $3+$ & 3.12 & 1.47 & 6.65 \\
\hline & Missing & 0.55 & 0.22 & 1.36 \\
\hline \multirow{6}{*}{$\begin{array}{l}\text { \#times had sex without } \\
\text { condom/ year }\end{array}$} & Never & 1.00 & & \\
\hline & $<$ Half of the time & 1.18 & 0.80 & 1.74 \\
\hline & Half of the time & 1.23 & 0.74 & 2.07 \\
\hline & $>$ Half of the time & 0.97 & 0.64 & 1.47 \\
\hline & Always & 1.06 & 0.78 & 1.44 \\
\hline & Missing & 0.68 & 0.43 & 1.07 \\
\hline \multirow{3}{*}{$\begin{array}{l}\text { Describe sexual } \\
\text { orientation }\end{array}$} & Heterosexual/straight & 1.00 & & \\
\hline & $\begin{array}{l}\text { Homosexual/lesbian/ } \\
\text { bisexual/other }\end{array}$ & 1.24 & 0.92 & 1.67 \\
\hline & Missing & 1.43 & 0.74 & 2.74 \\
\hline
\end{tabular}

\#Prevalence Ratio (PR). If the $95 \%$ Confidence Interval of the PR does not contain the value 1.0, the association between the HPV infection and factor is statistically significant $(p<0.05)$.

\section{Availability of supporting data}

All data used in this research can be downloaded from the following website: http://www.cdc.gov/nchs/nhanes/ nhanes_questionnaires.htm.

\section{Ethics statement}

Use of data from the NHANES 2007-2010 is approved by the National Center for Health Statistics (NCHS) Research Ethics Review Board (ERB) Approval for NHANES 20092010 (Continuation of Protocol \#2005-06), NHANES 2007-2008 (Continuation of Protocol \#2005-06) and NHANES 2005-2006 (Protocol \#2005-06).

\section{Abbreviations}

HPV: Human papillomavirus; NH: Non-hispanic; CDC: Centers for Disease Control and Prevention; NHANES: National Health and Nutrition Examination Survey; MEC: Mobile Examination Center; NCHS: National Center for Health Statistics; PCR: Polymerase chain reaction; DNA: Deoxyribonucleic acid; PIR: Income-to-poverty ratio; PR: Prevalence ratio; SAS: Statistical analysis system; SUDAAN: Survey data analysis. 


\section{Competing interests}

The authors have no financial or non-financial competing interests to disclose.

\section{Authors' contributions}

RS carried out design of the study, data management, statistical analysis, and writing of the manuscript. HT and SD helped to write and finalize the manuscript. LL conceived the study, participated in its design, and helped to write the manuscript. GM helped in the study's design and in writing the manuscript. All authors read and approved the final manuscript.

\section{Acknowledgements}

The authors wish to acknowledge the NHANES 2007-2010 participants and investigators as well as the National Center for Health Statistics and its Research Data Center for making the public data available. However, the authors take full and sole responsibility for the integrity of the data analysis and the contents of this article. We also wish to thank Talicia A. Tarver and Shenika McCary for their assistance in preparing this manuscript and the reviewers for their critical comments and suggestions.

Received: 23 April 2014 Accepted: 12 August 2014 Published: 18 August 2014

\section{References}

1. Human Papillomavirus (HPV) Vaccines. [http://www.cancer.gov/cancertopics/ factsheet/prevention/HPV-vaccine]

2. Hariri S, Unger ER, Sternberg M, Dunne EF, Swan D, Patel S, Markowitz LE: Prevalence of genital human papillomavirus among females in the United States, the National Health And Nutrition Examination Survey, 2003-2006. J Infect Dis 2011, 204(4):566-573.

3. CDC: Human Papillomavirus-Associated Cancers - United States, 2004-2008. MMWR Morb Mortal Wkly Rep 2012, 61(15):630-632.

4. Basic Information about HPV-Associated Cancers. [http://www.cdc.gov/ cancer/hpv/basic_info/]

5. Baseman JG, Koutsky LA: The epidemiology of human papillomavirus infections. J Clin Virol 2005, 32(Suppl 1):S16-24.

6. Gillison ML, Chaturvedi AK, Lowy DR: HPV prophylactic vaccines and the potential prevention of noncervical cancers in both men and women. Cancer 2008, 113(10 Suppl):3036-3046.

7. Cervical Cancer Statistics. http://www.cdc.gov/cancer/cervical/statistics/.

8. Questionnaires, Datasets, and Related Documentation. http://www.cdc.gov/ nchs/nhanes/nhanes_questionnaires.htm.

9. Johnson $\mathrm{CL}$, Paulose-Ram R, Ogden $\mathrm{CL}$ e: National Health and Nutrition Examination Survey: Analytic guidelines, 1999-2010. National Center for Health Statistics. Vital Health Stat 2 2013, 2(161):1-15.

10. Dunne EF, Unger ER, Sternberg M, McQuillan G, Swan DC, Patel SS, Markowitz LE: Prevalence of HPV infection among females in the United States. JAMA 2007, 297(8):813-819.

11. Steinau M, Swan DC, Unger ER: Type-specific reproducibility of the Roche linear array HPV genotyping test. J Clin Virol 2008, 42(4):412-414.

12. Onyekwuluje JM, Steinau M, Swan DC, Unger ER: A real-time PCR assay for HPV52 detection and viral load quantification. Clin Lab 2012, 58(1-2):61-66.

13. Gravitt PE, Peyton CL, Alessi TQ, Wheeler CM, Coutlee F, Hildesheim A Schiffman MH, Scott DR, Apple RJ: Improved amplification of genital human papillomaviruses. J Clin Microbiol 2000, 38(1):357-361

14. Sanders AE, Slade GD, Patton LL: National prevalence of oral HPV infection and related risk factors in the U.S. adult population. Oral Dis 2012, 18(5):430-441.

15. Korn E,B,G: Analysis of Health Surveys. New York, NY: Wiley; 1999.

16. Casella G, Berger R: Statistical Inference. Duxbury: Pacific Grove, CA; 1990.

17. RTI: SUDAAN Language Manual, Volumes 1 and 2, Release 11. First Editionth edition. Research Triangle Park, NC: Research Triangle Institute; 2012

18. Unger ER, Steinau M, Lin JMS, Patel SS, Swan DC: Impact of HPV Assay on Observed Population Prevalence. Diagn Mol Pathol 2011, 20(2):101-104.

19. Castle PE, Gravitt PE, Solomon D, Wheeler CM, Schiffman M: Comparison of linear array and line blot assay for detection of human papillomavirus and diagnosis of cervical precancer and cancer in the atypical squamous cell of undetermined significance and low-grade squamous intraepithelial lesion triage study. J Clin Microbiol 2008, 46(1):109-117.
20. Bosch FX, Burchell AN, Schiffman M, Giuliano AR, de Sanjose S, Bruni L, Tortolero-Luna G, Kjaer SK, Munoz N: Epidemiology and Natural History of Human Papillomavirus Infections and Type-Specific Implications in Cervical Neoplasia. Vaccine 2008, 26:K1-K16.

21. de Sanjose S, Diaz M, Castellsague X, Clifford G, Bruni L, Munoz N, Bosch FX: Worldwide prevalence and genotype distribution of cervical human papillomavirus DNA in women with normal cytology: a meta-analysis. Lancet Infect Dis 2007, 7(7):453-459.

22. Garcia-Pineres AJ, Hildesheim A, Herrero R, Trivett M, Williams M, Atmetlla I, Ramirez M, Villegas M, Schiffman M, Rodriguez AC, Burk RD, Hildesheim M, Freer E, Bonilla J, Bratti C, Berzofsky JA, Pinto LA: Persistent human papillomavirus infection is associated with a generalized decrease in immune responsiveness in older women. Cancer Res 2006, 66(22):11070-11076.

23. Finer LB: Trends in premarital sex in the United States, 1954-2003. Public Health Rep 2007, 122(1):73-78.

24. Arbyn M, de Sanjose S, Saraiya M, Sideri M, Palefsky J, Lacey C, Gillison M, Bruni L, Ronco G, Wentzensen N, Brotherton J, Qiao YL, Denny L, Bornstein J, Abramowitz L, Giuliano A, Tommasino M, Monsonego J: EUROGIN 2011 roadmap on prevention and treatment of HPV-related disease. Int J Cancer 2012, 131(9):1969-1982.

25. Applebaum KM, Furniss CS, Zeka A, Posner MR, Smith JF, Bryan J, Eisen EA, Peters ES, McClean MD, Kelsey KT: Lack of association of alcohol and tobacco with HPV16-associated head and neck cancer. J Natl Cancer Inst 2007, 99(23):1801-1810.

26. Marek E, Dergez T, Rebek-Nagy G, Szilard I, Kiss I, Ember I, Gocze P, D'Cruz G: Effect of an educational intervention on Hungarian adolescents' awareness, beliefs and attitudes on the prevention of cervical cancer. Vaccine 2012, 30(48):6824-6832.

27. Markowitz LE, Hariri S, Lin C, Dunne EF, Steinau M, McQuillan G, Unger ER: Reduction in human papillomavirus (HPV) prevalence among young women following HPV vaccine introduction in the United States, National Health and Nutrition Examination Surveys, 2003-2010. J Infect Dis 2013, 208(3):385-393.

28. Ratanasiripong NT: A Review of Human Papillomavirus (HPV) Infection and HPV Vaccine-Related Attitudes and Sexual Behaviors among College-Aged Women in the United States. J Am Coll Health 2012, 60(6):461-470.

29. Pourat N, Jones JM: Role of insurance, income, and affordability in human papillomavirus vaccination. Am J Manag Care 2012, 18(6):320-330.

doi:10.1186/1756-0500-7-544

Cite this article as: Shi et al.: Factors associated with genital human papillomavirus infection among adult females in the United States, NHANES 2007-2010. BMC Research Notes 2014 7:544.

\section{Submit your next manuscript to BioMed Central and take full advantage of:}

- Convenient online submission

- Thorough peer review

- No space constraints or color figure charges

- Immediate publication on acceptance

- Inclusion in PubMed, CAS, Scopus and Google Scholar

- Research which is freely available for redistribution 